\title{
Article \\ Changes in Spinal-Reflex Excitability during Static Stretch and/or Explosive Contraction
}

\author{
Kyeong Eun Min ${ }^{1}$, YongSuk Lee ${ }^{2}$ and Jihong Park ${ }^{3, *}$ (i) \\ 1 Athletic Training Laboratory, Department of Physical Education, Graduate School, Kyung Hee University, \\ Yongin 17104, Korea; mke92@khu.ac.kr \\ 2 Athletic Training Laboratory, Department of Sports Medicine and Science, Graduate School of Physical \\ Education, Kyung Hee University, Yongin 17104, Korea; donkey00@khu.ac.kr \\ 3 Athletic Training Laboratory, Department of Sports Medicine, Kyung Hee University, Yongin 17104, Korea \\ * Correspondence: jihong.park@khu.ac.kr; Tel.: +82-31-201-2721
}

check for updates

Citation: Min, K.E.; Lee, Y.; Park, J. Changes in Spinal-Reflex Excitability during Static Stretch and/or Explosive Contraction. Appl. Sci. 2021, 11, 2830. https://doi.org/ 10.3390/app11062830

Academic Editor: Nyeonju Kang

Received: 2 March 2021

Accepted: 19 March 2021

Published: 22 March 2021

Publisher's Note: MDPI stays neutral with regard to jurisdictional claims in published maps and institutional affiliations.

Copyright: (c) 2021 by the authors. Licensee MDPI, Basel, Switzerland. This article is an open access article distributed under the terms and conditions of the Creative Commons Attribution (CC BY) license (https:// creativecommons.org/licenses/by/ $4.0 /)$.

\begin{abstract}
To examine individual or combined effects of static stretch and explosive contraction on quadriceps spinal-reflex excitability (the peak Hoffmann's reflex normalized by the peak motorresponse) and the latency times of the Hoffmann's reflex and motor-response. Fourteen healthy young males randomly experienced four conditions (stretch, contraction, stretch + contraction, and control-no intervention). For the stretch condition, three sets of a $30 \mathrm{~s}$ hold using the modified Thomas test on each leg were performed. For the contraction condition, three trials of maximal countermovement vertical jump were performed. Quadriceps spinal-reflex excitability and the latent period of each value on the right leg were compared at pre- and post-condition. All measurement values across conditions were not changed at any time point (condition $\times$ time) in spinal-reflex excitability $\left(\mathrm{F}_{6,143}=1.10, p=0.36\right)$, Hoffmann's reflex latency $\left(\mathrm{F}_{6,143}=0.45, p=0.84\right)$, motor-response latency $\left(\mathrm{F}_{6,143}=0.37, p=0.90\right)$, and vertical jump heights $\left(\mathrm{F}_{2,65}=1.82, p=0.17\right)$. A statistical trend was observed in the contraction condition that spinal-reflex excitability was increased by $42 \%$ (effect size: 0.63$)$. Neither static stretch nor explosive contraction changed the quadriceps spinal-reflex excitability, latency of Hoffmann's reflex, and motor-response. Since our stretch protocol did not affect jumping performance and our contraction protocol induced the post-activation potentiation effect, either protocol could be used as pre-exercise activity.
\end{abstract}

Keywords: H:M ratio; Thomas test; vertical jump

\section{Introduction}

Performance enhancement after warm-up activity could be explained by thermal and non-thermal effects. While the term "warm-up" is derived from the thermal effects due to any given activity (e.g., increased core body and local muscle temperatures), "preconditioning" [1], the working of muscles by performing sports movements (e.g., explosive movements), is considered to contribute the non-thermal effects of warming-up [2]. Assuming the thermal effects are similar, the level of performance among different types of warm-up would be affected by the ability to utilize elastic energy [3]. Elastic energy is associated with muscle spindle activity [4], myotatic reflex [5], and elasticity of contractile components [6]. Measures of elastic energy are difficult because they are derived from various structures (e.g., actin, myosin, sarcolemma, tendon, etc.) that are instantiated through different neural pathways (e.g., $\alpha$ and $\gamma$ motoneuron). Spinal-reflex excitability, Hoffmann (H)-reflex [7] normalized by the motor (M)-response (H:M ratio), is an autonomic homonymous response to a given peripheral (especially Ia afferent) stimulus [8]. Exogenous electrical stimuli should directly evoke afferents; the H-reflex bypasses the signals of muscle spindles and $\gamma$-motoneurons [9]. It has been suggested that the magnitude of the stretch-reflex is related to the amount of stored elastic energy $[10,11]$. The amplitude of this value is indicative of synaptic transmission [2], spinally mediated neural 
inhibition [12], and an estimate of $\alpha$-motoneuron activity [13]. Additionally, the assessment of the H-reflex and M-response latency time are also considered to be parameters affecting synaptic transmission along with performance change [14]. Therefore, the non-thermal effects of warming-up in terms of enhancing elastic potential energy could be assessed by spinal-reflex excitability and the latency times of the H-reflex and the M-response.

Previous studies concerning the acute change in the soleus H-reflex reported a reduction after static stretch $[15,16]$ and an increase after muscle contractions $[17,18]$. Although the existing data inform us how the H-reflex responds to stretch or contraction, several limitations still need to be addressed. First, spinal-reflex excitability in the quadriceps has not been examined even though it is the primary muscle for functional movements $[19,20]$. Second, subjects in previous reports examined isometric contractions [17,18], which are not commonly performed during warming-up or training. Third, the combined effect of stretch and contraction is unknown. For example, reduced spinal-reflex excitability after performing static stretch might be offset by performing muscle contractions such as maximal vertical jumps. This indicates that static stretch does not produce performance hinderance if vertical jumps are followed. Knowing the direction and magnitude of change in spinally mediated muscle activation of quadriceps responding to static stretch and/or explosive contraction would help coaches and athletes to plan and execute pre-exercise activities. While the general hesitance of static stretch to hamper muscle power in the field of exercise science still exists, comparing jump heights before and after static stretch would also provide a comprehensive understanding of the relationships among static stretch, quadriceps spinal-reflex excitability, and athletic performance.

A comparison of the individual and combined effects of static stretch (e.g., hip and knee extensors) and explosive contraction (e.g., maximal vertical jump) could address the limitations above, and thus provide information on the relationship between spinal-reflex excitability and athletic performance as well as the interaction effect between muscle stretch and contraction. Therefore, the purpose of this study was to examine the immediate effects of static stretch and/or two-legged maximal vertical jump on quadriceps spinal-reflex excitability, and the latency time of the H-reflex and M-response, compared with no activity which served as the control. Based on previous reports on the soleus H-reflex [15-18], it can be hypothesized that quadriceps spinal-reflex excitability would be decreased after stretching and increased after contracting (jumping). Since change in quadriceps spinalreflex excitability after stretch or contraction is unknown, it is difficult to predict the result of the combined condition (stretch and contraction). If the magnitudes of change after stretch or contraction were similar, the effects of two stimuli would be cancelled out, resulting in no change. While change in the latency time can be indicative of temporal change in neural activation, a previous study [21] reported that static stretch or vibration did not change the H-reflex and M-response latency time in the soleus. According to that, we hypothesized no change in the H-reflex and M-response latency time across the four conditions.

\section{Materials and Methods}

\subsection{Subjecs}

We recruited recreationally active male individuals (aged between 19 and 25; exercise $>3$ times a week at moderate intensity; a total exercise duration between $150 \mathrm{~min}$ and $250 \mathrm{~min}$ for the last six months) who had a measurable quadriceps (vastus medialis: VM) H-reflex and M-response. Subjects had no history of lower-back or -body surgery and were free from lower-back or -body injuries in the past six months. Subjects with athletic career (experience of registration in the varsity team roaster or participation in an official sporting event) or cardiovascular or neurological pathology were also excluded. Fifty-four subjects were initially screened, and 40 of them were excluded due to immeasurable H-reflex $(n=38)$ and unstable M-response $(n=2)$. Therefore, fourteen subjects (age: $23 \pm 1$ years; height: $175 \pm 7 \mathrm{~cm}$; mass: $69 \pm 8 \mathrm{~kg}$; exercise duration: $220 \pm 79.4 \mathrm{~min} /$ week) were finally 
analyzed. Prior to participation, all subjects gave informed consent, approved by the university's Institutional Review Board, which also approved the study.

\subsection{Testing Procedures}

All subjects visited the laboratory four times on separate days at the same time of the day, $48 \mathrm{~h}$ apart. Subjects were asked to maintain their habitual diets during the experimental period and to refrain from any physical activity for $24 \mathrm{~h}$ prior to data collection. For the first session, subjects were screened for measurable $\mathrm{H}$-reflex after providing informed consent. Ambient temperature and relative humidity within the laboratory were set as $25^{\circ} \mathrm{C}$ and $50 \%$ during the data collection period. Upon arrival to the laboratory, subjects laid down on the treatment table and rested for $15 \mathrm{~min}$ to achieve spinal-reflex and cardiovascular stability prior to the screening. During this rest period, the VM on the dominant limb (i.e., the leg used to kick a ball) were shaved, debrided (with sandpaper), and cleaned with alcohol prep wipes before the placement of self-adhesive surface electromyography (EMG) electrodes (Ag-AgCI; EL 503-10; Biopac System Inc., Goleta, CA, USA). Two EMG electrodes $(2 \mathrm{~cm}$ apart) were attached to the bulk of the VM. The ground electrode was attached to the medial malleolus of the ipsilateral limb.

During the H-reflex and M-response measurements, subjects were asked to place their hands along their sides with their palms kept supinated and to maintain this position as they looked at a spot on the ceiling while listening to white noise through earphones to avoid any possible sound-induced variability in measurements [22]. The stimulating module (Biopac STM 100C), isolation adaptor (Biopac Stimsoc), and a bar stimulation electrode (EL 503, Biopac Systems Inc., Goleta, CA, USA) provided the electrical stimulus over the femoral nerve (just lateral and/or down to the femoral artery). The peak H-reflex and peak M-response were found and recorded through surface EMG (sampling rate: $2000 \mathrm{~Hz}$ ). Electrical stimulation was gradually increased at 0.1-2 V increments, with a $15 \mathrm{~s}$ rest between stimulations [23]. The average intensities (ranges) to elicit the peak H-reflex and the peak M-response were 6.0 (4.0 to 9.0) and 9.3 (7.1 to 10.0) V, respectively. Once peak amplitude was found, the same intensity was applied four times for the pre-condition measurements.

After the pre-condition measurements, the researcher who took measurements left, and the other researcher who was blinded to pre-condition measurements guided the intervention conditions in the laboratory. Subjects randomly experienced one of four conditions on each visit (stretch, contraction, stretch and contraction, and control: Figure 1). The order of the conditions for each subject was determined by the opaque envelope method. For the stretch condition, the modified Thomas test [24] was used. Subjects were asked to seat at the end of a treatment table and roll back onto the table while bending and pulling one of the knees to their chest. Once subjects were in the position, the researcher gradually provided manual stretch force (Figure 2). Subjects were asked to stop the researcher when they felt stretch sensation [25] or the point of discomfort [26], then this end position was held for $30 \mathrm{~s}$, which was timed by the researcher. Three repetitions on each leg were alternatively performed (a total duration of $90 \mathrm{~s}$ with a rest interval of $30 \mathrm{~s}$ ). For the contraction condition, subjects performed two-legged countermovement maximal vertical jumps on Vertec (Sports Imports, Hilliard, OH, USA). Subjects' standing arm reach height was measured with a Vertec. Subjects stood (same feet positions for vertical jumps) and maintained their lower-extremity full extension and trunk upright and raised (full scapular upward rotation with abduction) their dominant arm (i.e., the arm throwing a ball) directly overhead as high as possible. Subjects were then asked to vertically jump off of both legs as high as they possibly could and touch the plastic vane of the Vertec (this instruction was given during the standing arm height measurement). A self-selected pre-stretch of the lower-body and trunk and double-arm swinging at take-off were allowed. Three trials were performed, with a $30 \mathrm{~s}$ rest interval between jumps. For the stretch and contraction condition, the order of stretch and contraction interventions, described above, was performed. In the case of the conditions with contraction (contraction, and stretch and 
contraction), subjects performed a total of nine countermovement vertical jumps (condition: $\times 3$; post-condition at $0 \mathrm{~min}$; $\times 3$; post-condition at $20 \mathrm{~min}: \times 3$; Figure 1 ). For the control condition, subjects neither performed stretching nor jumping but maintained a supine position on the treatment table. In this study, interventions (stretch and/or jump) were performed without specific warm-up activity to eliminate the potential confounding effects of change in tissue temperature or energy expenditure.

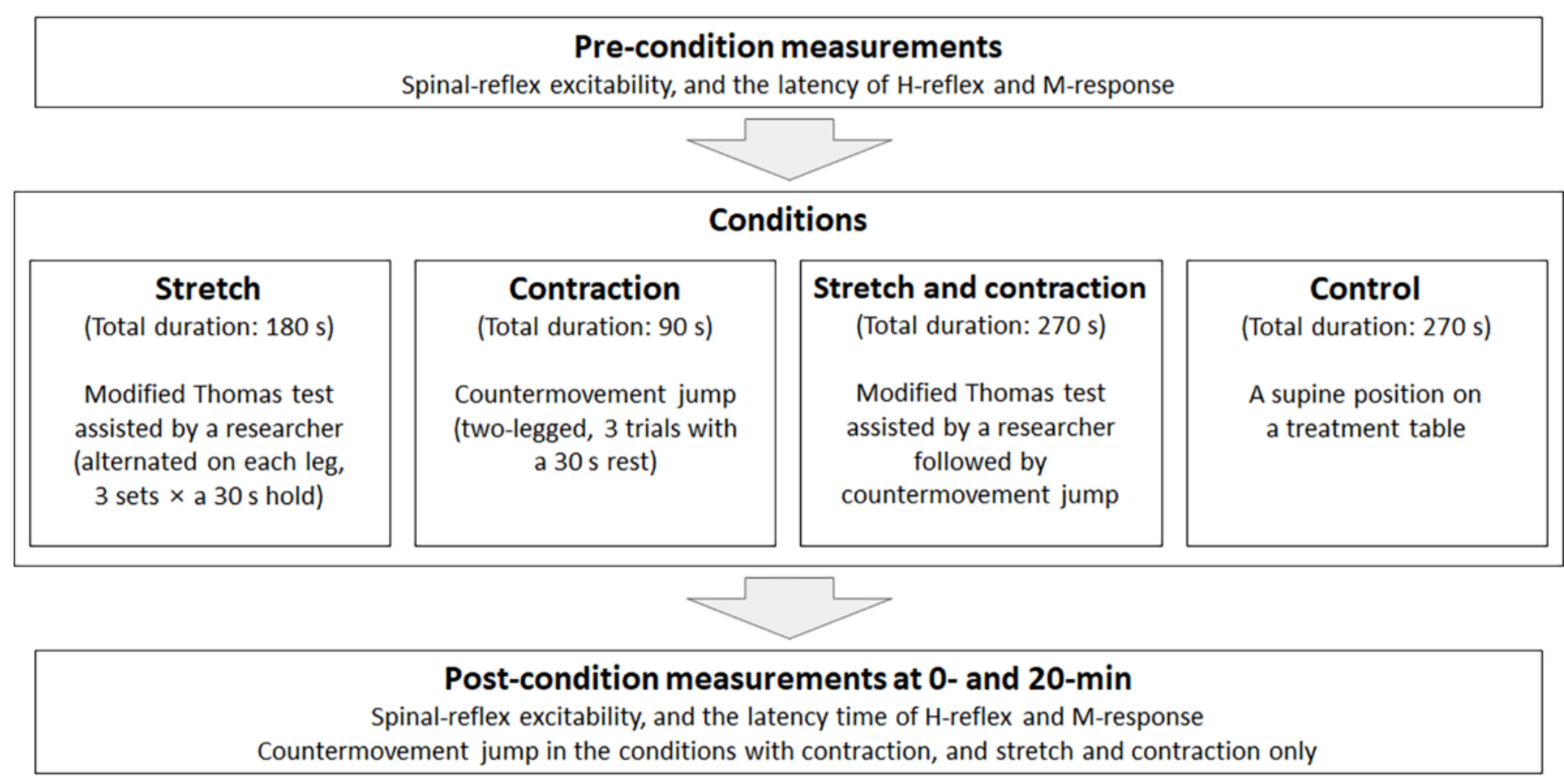

Figure 1. Testing procedures. Countermovement jumps were performed in the conditions with contraction (contraction, and stretch and contraction) during the conditions $(\times 3)$, and post-condition at $0(\times 3)$ and $20 \mathrm{~min}(\times 3)$.

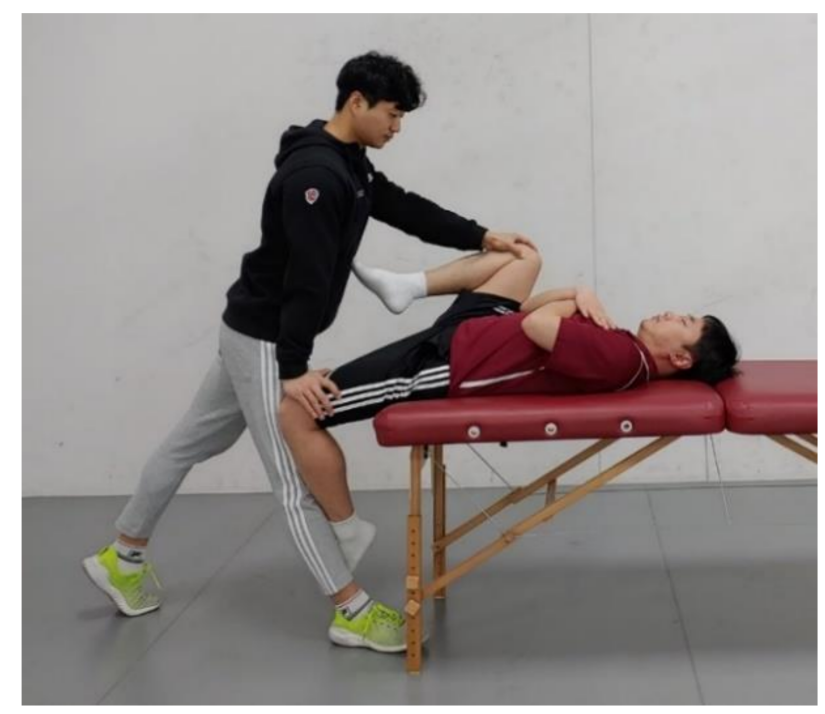

Figure 2. A subject performing stretch using the modified Thomas test. The researcher gradually provided an additional tensional force until the patient felt a self-selected moderate discomfort, then held the position for $30 \mathrm{~s}$. The left hip flexors and right knee extensors are being stretched.

After the conditions, the researcher who guided the interventions left, and the other researcher who obtained measurements came into the laboratory. The post-condition measurements at 0 and 20 min were subsequently taken in the same manner as the precondition. 


\subsection{Data Reduction}

The H:M ratio (the peak H-reflex normalized by the peak M-response) was calculated to obtain spinal-reflex excitability [27]. The latency times for the peak H-reflex and the peak M-response were also analyzed. Latent period was defined as the time between the stimulation onset and the peak H-reflex or the peak M-response [28]. Two-legged countermovement maximal vertical jump heights were calculated by subtracting the height of standing arm reach from the jump height. Jump height values were read in inches on Vertec then converted into centimeters.

\subsection{Statistical Analysis}

Our sample size was determined using an expected change in the H:M ratio of 0.12 and a standard deviation of 0.15 , which yielded an effect size (ES) of 0.8 [29]. This estimation with an $\alpha$ of 0.05 and a $\beta$ of 0.2 resulted in 13 individuals necessary in each condition.

To test condition effect over time, a mixed model analysis of variance (random variable: subjects; fixed variables: condition and time) was performed in the quadriceps spinal-reflex excitability and the latency of the H-reflex and M-response $(4 \times 3)$ and countermovement maximal vertical jump $(2 \times 3)$. Tukey-Kramer pairwise comparisons were performed for post-hoc tests $(p \leq 0.05)$. To determine practical significance, between-time ES were also calculated [30]. To obtain measurement consistency on within- and between-session, twoway mixed model analysis of variance was performed using the pre-condition measurement values. Between-subject mean square and error mean square were then inserted into the formula to gain intraclass correlation coefficient (ICC) [31]. All data were analyzed using a statistical package SAS 9.4.

\section{Results}

\subsection{Spinal-Reflex Excitability}

We did not observe condition effect over time in quadriceps spinal-reflex excitability (condition $\times$ time: $\mathrm{F}_{6,143}=1.10, p=0.36$; time effect: $\mathrm{F}_{2,143}=0.05, p=0.95$; Table 1). Regardless of time (condition effect: $\mathrm{F}_{3,143}=2.39, p=0.07$ ), statistical trends showed there was greater spinal-reflex excitability in the contraction condition than the stretch $(p=0.03$, $\mathrm{ES}=0.35,19 \%)$ or stretch and contraction $(p=0.05, \mathrm{ES}=0.36,18 \%)$ conditions (Figure 3 ). An additional statistical trend was observed (Figure 4) in the contraction condition such that spinal-reflex excitability increased (pre- vs. post-condition at $0 \mathrm{~min}: p=0.03, \mathrm{ES}=0.63$, $42 \%$ ) and the increased value was sustained for $20 \mathrm{~min}$ (pre- vs. post-condition at $20 \mathrm{~min}$ : $p=0.11, \mathrm{ES}=0.46,23 \%)$.

Table 1. Change in spinal-reflex excitability.

\begin{tabular}{ccccc}
\hline & Stretch & Contraction & Stretch and Contraction & Control \\
\hline Pre-condition & 0.24 & 0.22 & 0.24 & 0.26 \\
Post-condition at & $(0.18$ to 0.30$)$ & $(0.17$ to 0.27$)$ & $(0.17$ to 0.31$)$ & $(0.19$ to 0.33$)$ \\
0 min & 0.20 & 0.31 & 0.21 & 0.26 \\
Post-condition at & 0.14 to 0.26$)$ & $(0.22$ to 0.40$)$ & $(0.13$ to 0.29$)$ & $(0.20$ to 0.32$)$ \\
20 min & $(0.18$ to 0.26$)$ & $(0.19$ to 0.37$)$ & 0.22 & 0.26 \\
\end{tabular}

The values are mean (lower and upper bounds of $95 \%$ confidence intervals). 


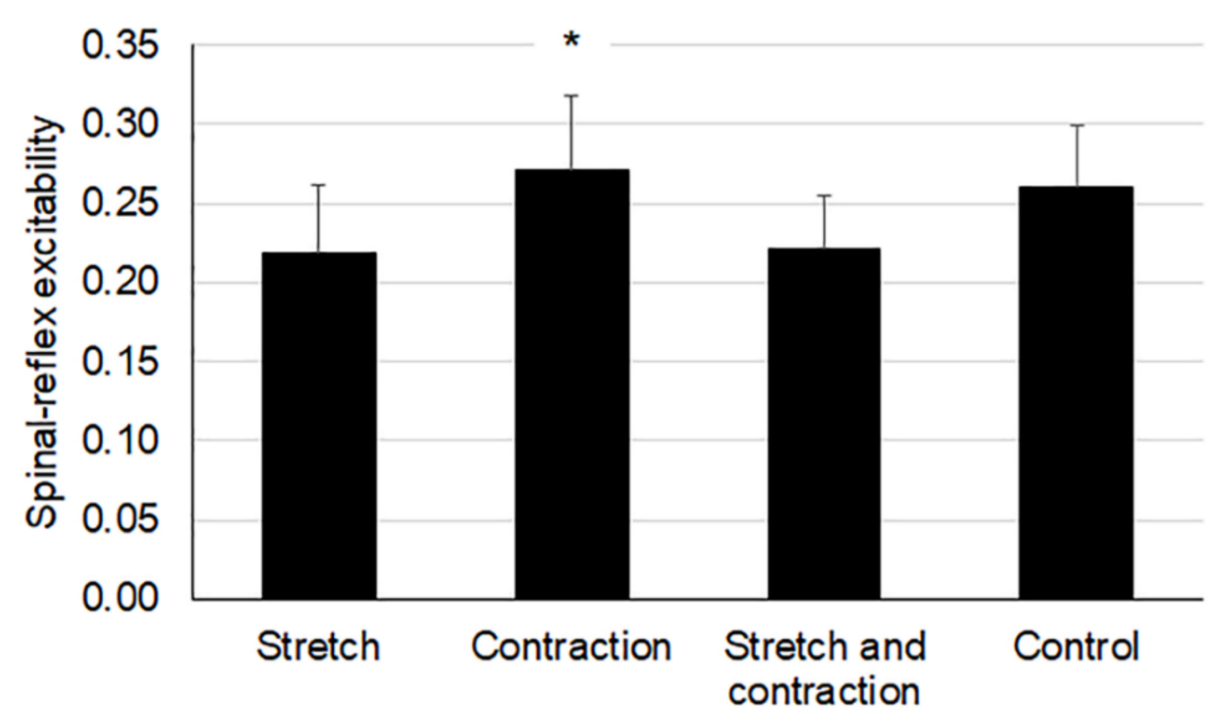

Figure 3. Change in quadriceps spinal-reflex excitability (time-collapsed: condition effect: $\left.\mathrm{F}_{3,143}=2.39, p=0.07\right)$. ${ }^{*}$ Different from the stretch condition $(p=0.03, \mathrm{ES}=0.35,19 \%)$ and stretch and contraction condition $(p=0.05, \mathrm{ES}=0.36,18 \%)$.

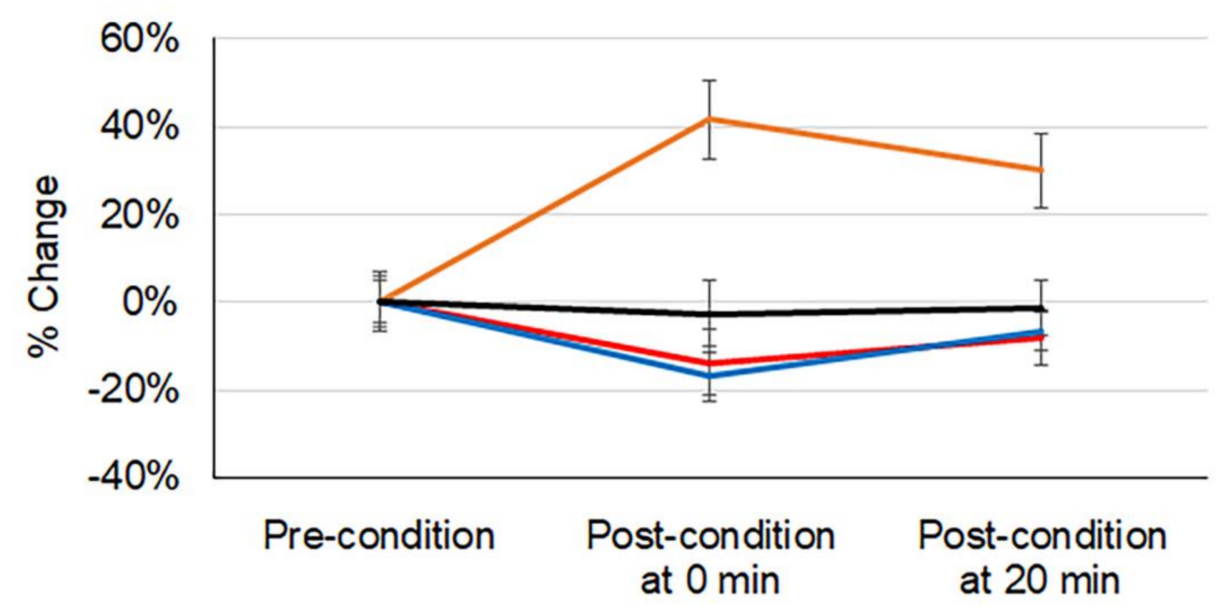

\section{- Stretch - Contraction - Stretch and contraction - Control}

Figure 4. Quadriceps spinal-reflex excitability expressed as percentage change from the pre-condition measurement. Error bars are upper and lower values of $95 \%$ confidence intervals. After the contraction condition, quadriceps spinal-reflex excitability was increased at post-condition at $0 \mathrm{~min}(42 \%$, $\mathrm{ES}=0.63)$, and the increased value was maintained for $20 \mathrm{~min}(30 \%, \mathrm{ES}=0.46)$.

\subsection{Latency of the H-Reflex and M-Response}

The peak H-reflex latency (condition $\times$ time: $\mathrm{F}_{6,143}=0.45, p=0.84$; condition effect: $\mathrm{F}_{3,143}=3.40, p=0.02$; time effect: $\mathrm{F}_{2,143}=1.74, p=0.18$; Table 2) and the peak M-response latency (condition $\times$ time: $\mathrm{F}_{6,143}=0.37, p=0.90$; condition effect: $\mathrm{F}_{3,143}=1.30, p=0.28$; time effect: $F_{2,143}=1.20, p=0.30$; Table 2) were analyzed. 
Table 2. Change in the latency time.

\begin{tabular}{|c|c|c|c|c|c|c|c|c|}
\hline & \multicolumn{4}{|c|}{ Peak H-Reflex (ms) } & \multicolumn{4}{|c|}{ Peak M-Response (ms) } \\
\hline & Stretch & Contraction & $\begin{array}{l}\text { Stretch and } \\
\text { Contraction }\end{array}$ & Control & Stretch & Contraction & $\begin{array}{l}\text { Stretch and } \\
\text { Contraction }\end{array}$ & Control \\
\hline Pre-condition & $\begin{array}{c}17.2 \\
(16.1 \text { to } 18.3)\end{array}$ & $\begin{array}{c}17.6 \\
(16.6 \text { to } 18.6)\end{array}$ & $\begin{array}{c}17.4 \\
(16.2 \text { to } 18.6)\end{array}$ & $\begin{array}{c}16.3 \\
\text { (5.2 to } 17.4)\end{array}$ & $\begin{array}{c}6.3 \\
(6.0 \text { to } 6.6)\end{array}$ & $\begin{array}{c}6.3 \\
(6.0 \text { to } 6.6)\end{array}$ & $\begin{array}{c}6.1 \\
(5.8 \text { to } 6.4)\end{array}$ & $\begin{array}{c}6.1 \\
\text { (5.5 to } 6.7)\end{array}$ \\
\hline Post-condition & 16.8 & 16.7 & 16.9 & 16.0 & 6.2 & 6.1 & 6.1 & \\
\hline $\begin{array}{l}\text { at } 0 \text { min } \\
\text { Post-condition }\end{array}$ & $\begin{array}{c}(15.4 \text { to } 18.2) \\
16.0\end{array}$ & $\begin{array}{c}\text { (15.6 to } 17.8) \\
17.0\end{array}$ & $\begin{array}{c}(15.6 \text { to } 18.2) \\
17.2\end{array}$ & $\begin{array}{c}(14.9 \text { to } 17.1) \\
16.1\end{array}$ & $\begin{array}{l}(5.9 \text { to } 6.5) \\
6.4\end{array}$ & $\begin{array}{c}(5.8 \text { to } 6.4) \\
6.2\end{array}$ & $\begin{array}{l}(5.8 \text { to } 6.4) \\
6.4\end{array}$ & $\begin{array}{c}\text { (5.5 to } 6.7) \\
6.1\end{array}$ \\
\hline at $20 \mathrm{~min}$ & (14.6 to 17.4 ) & (15.9 to 18.1 ) & (16.0 to 18.4 ) & (15.1 to 17.1 ) & (5.9 to 6.9 ) & (5.8 to 6.6 ) & (6.0 to 6.8 ) & (5.6 to 6.6 ) \\
\hline
\end{tabular}

The values are mean (lower and upper bounds of $95 \%$ confidence intervals).

\subsection{Two-Legged Maximal Countermovement Vertical Jump}

Two-legged countermovement maximal vertical jump heights did not differ between conditions at any time point (condition $\times$ time: $\mathrm{F}_{2,65}=1.82, p=0.17$; time effect: $\mathrm{F}_{2,65}=0.21$, $p=0.81$; Table 3). Regardless of time (condition effect: $\mathrm{F}_{1,65}=10.09, p=0.002$ ), subjects in the stretch and contraction condition $(49.8 \mathrm{~cm})$ jumped higher than in the contraction condition $(48.6 \mathrm{~cm}, \mathrm{ES}=0.12)$.

Table 3. Change in two-legged countermovement maximal vertical jump height.

\begin{tabular}{ccc}
\hline Unit: $\mathbf{c m}$ & Contraction & Stretch and Contraction \\
\hline Condition & $48.4(43.2$ to 53.6$)$ & $50.1(45.3$ to 54.9$)$ \\
Post-condition at $0 \mathrm{~min}$ & $48.6(43.4$ to 53.8$)$ & $50.0(45.1$ to 54.9$)$ \\
Post-condition at $20 \mathrm{~min}$ & $49.0(43.7$ to 54.3$)$ & $49.1(44.1$ to 54.1$)$ \\
\hline
\end{tabular}

The values are mean (lower and upper bounds of $95 \%$ confidence intervals). Note that the conditions with stretch and control did not perform maximal vertical jumps.

\subsection{Measurement Consistency}

Measurement consistency for each dependent variable at pre-condition was moderate to high (ICC values in spinal-reflex excitability: 0.85 to 0.99 ; H-reflex latency: 0.63 to 0.99 ; M-response latency: 0.77 to 0.99 ; and maximal countermovement vertical jump height: 0.93 to 0.97$)$. All values including mean, standard deviation, and standard error of measurement (SEM) are presented in Table 4.

Table 4. Mean (SD), ICC, and SEM of spinal-reflex excitability, H-reflex and M-response latency time, and two-legged countermovement maximal vertical jump height at the pre-condition values.

\begin{tabular}{ccccc}
\hline Condition & Measurements & Mean (SD) & ICC & SEM \\
\hline \multirow{3}{*}{ Stretch } & Spinal-reflex excitability & $0.24(0.14)$ & 0.99 & 0.01 \\
& Peak H-reflex latency & $17.18(2.03)$ & 0.99 & 0.20 \\
& Peak M-response latency & $6.29(0.61)$ & 0.99 & 0.06 \\
\hline \multirow{5}{*}{ Contraction } & Spinal-reflex excitability & $0.22(0.10)$ & 0.97 & 0.02 \\
& Peak H-reflex latency & $17.57(1.91)$ & 0.99 & 0.19 \\
& Peak M-response latency & $6.29(0.61)$ & 0.99 & 0.06 \\
& Maximal vertical jump height & $48.4(10.0)$ & 0.96 & 1.81 \\
\hline \multirow{3}{*}{ Stretch and } & Spinal-reflex excitability & $0.24(0.12)$ & 0.99 & 0.01 \\
& Peak H-reflex latency & $17.36(2.21)$ & 0.99 & 0.21 \\
& Peak M-response latency & $6.07(0.62)$ & 0.99 & 0.06 \\
& Maximal vertical jump height & $50.1(9.1)$ & 0.97 & 1.83 \\
\hline \multirow{2}{*}{ Control } & Spinal-reflex excitability & $0.26(0.14)$ & 0.99 & 0.02 \\
& Peak H-reflex latency & $16.27(2.10)$ & 0.99 & 0.20 \\
& Peak M-response latency & $6.07(0.62)$ & 0.99 & 0.06 \\
\hline
\end{tabular}


Table 4. Cont.

\begin{tabular}{ccccc}
\hline Condition & Measurements & Mean (SD) & ICC & SEM \\
\hline \multirow{3}{*}{ Intersession } & Spinal-reflex excitability & $0.24(0.12)$ & 0.85 & 0.05 \\
& Peak H-reflex latency & $17.09(2.07)$ & 0.63 & 1.24 \\
& Peak M-response latency & $6.18(0.61)$ & 0.77 & 0.29 \\
& Maximal vertical jump height & $47.2(10.5)$ & 0.93 & 2.73 \\
\hline
\end{tabular}

Unit: $\mathrm{ms}$ for latency of the H-reflex and M-response and $\mathrm{cm}$ for maximal vertical jump height. Note that the stretch and control condition did not perform vertical jump. SD: standard deviation; ICC: intraclass correlation coefficient; SEM: standard error of measurement.

\section{Discussion}

The primary objective of our study was to observe immediate changes in quadriceps (VM) spinal-reflex excitability in response to static stretch and/or explosive contraction. The spinal-reflex excitability remained unchanged across conditions (stretch, contraction, stretch and contraction, control) by time (pre- to post-condition). However, our hypotheses that the quadriceps spinal-reflex excitability would be reduced by stretch or increased by contraction were partially supported by trends in the condition effect (time-collapsed, $p=0.07$ : Figure 3). Based on the results of the condition effect, static stretch seemed to attenuate the spinal-reflex excitability when combined with explosive contraction or not. Statistical trends (Figure 4) in each condition over time also support the hypothesized direction of change. However, small to moderate ESs (0.35 to 0.63$)$ indicate that these spinalreflex excitability changes in responding to static stretch and/or explosive contraction are small. As expected, the latency time in H-reflex and M-response did not change among conditions over time. According to many other studies [21,32], this observation suggests that muscle stretch or contraction does not alter the latency time.

\subsection{Static Stretch and Jumping Performance}

Although a large body of research [33-35] has shown decreases in athletic performance such as vertical jump, static stretch is still considered as a part of warm-up routines due to gains of tissue compliance [36], potential injury reduction [37], and performance enhancement [38]. Therefore, the practical importance of static stretch on countermovement vertical jump heights was tested as the secondary aim. Our stretch protocol volume ( 3 sets $\times 30 \mathrm{~s}$ hold, alternated on each leg) did not change jumping performance, which is in line with the study in which the same stretch volume was administered [39,40]. Overall jump heights (statistical condition effect) between the condition of contraction $(48.6 \mathrm{~cm})$ and stretch and contraction $(49.8 \mathrm{~cm})$ were different, but it is not a meaningful observation since the amount of difference was within the SEM $(2.73 \mathrm{~cm})$ and a small ES (0.12). Previously, a $60 \mathrm{~s} \mathrm{[41]} \mathrm{or} 90 \mathrm{~s}$ [42] hold static stretch on lower extremity led to a reduction in maximal vertical jump. Taken together, the use of intermittent static stretch may have a minimal or no detrimental effect on subsequent explosive performance, although the total duration of static stretch (90 s) exceeded the previously suggested threshold duration (> $60 \mathrm{~s}$ ) [43,44]. Since nether the spinal-reflex excitability nor vertical jump heights show statistical changes, we do not know how the spinal-reflex excitability influenced vertical jump height. With scientific evidence on muscle spindle activation and $\alpha$-motoneuron facilitation [45], our observation could be interpreted in a couple of ways: (1) Regardless of the magnitude, changed spinal-reflex excitability has a minimal effect on jumping performance; or (2) altered spinal-reflex excitability in this study was small, which was insufficient to affect explosive contraction. Examining spinal-reflex excitability along with other explanatory factors that include biomechanical and physiological variables during altered jump height after static stretch would provide better understanding of the causal relationship and mechanisms that affect jump height after static stretch. 


\subsection{Quadriceps Spinal-Reflex Excitability after Static Stretch and/or Explosive Contraction}

Our study was the first attempt to observe changes in quadriceps spinal-reflex excitability in responding to static stretch and/or explosive contraction. The H-reflex is a monosynaptic response that is modulated by the magnitude of Ia sensory input and the sensitivity of muscle spindle activity [46]. The endings of muscle spindles respond to change in muscle length (e.g., speed and size) such as a quick muscle stretch or artificial electrical stimulation [47]. Stimulation of Golgi tendon organ after a certain period of static stretch (e.g., $>6 \mathrm{~s}$ ) overrides the impulses from the muscle spindles [48]. A decreased $\mathrm{H}$-reflex after static stretch (e.g., via autogenic inhibition), therefore, could be interpreted as an inhibition of muscle spindle activity. This could be further indicative of a reduction in muscle activation and force development due to the innervation of $\alpha-\gamma$ coactivation system to muscle spindles [46]. Our hypotheses were based on previous studies that reported changes in the soleus H-reflex after static stretch $[15,16]$ and isometric contraction $[17,18]$. We, however, did not observe such change (e.g., a statistical interaction on condition by time) in terms of quadriceps spinal-reflex excitability. We are unsure if changes in quadriceps spinal-reflex excitability are dose-dependent, and the volume of our stretch or contraction protocol did not reach the threshold point when excitability begins to alter significantly from baseline. Future studies should attempt to find this threshold, in terms of the volume and intensity, on quadriceps spinal-reflex excitability.

\subsection{Statistical Trends and the Combined Effect}

We observed there was a $14 \%$ reduction $(E S=0.27)$ after static stretch and a $42 \%$ increase $(E S=0.63)$ after explosive contraction in the spinal-reflex excitability. Although moderate, the calculated ES after vertical jumps (contraction condition) supports the general idea that muscle contractions (preconditioning) acutely produce the post-activation potentiation (PAP) effect, especially on spinal-level excitability [49,50]. Considering the importance of VM activation during functional movements [51,52], the facilitative effect after explosive contraction also has the practical implication that a countermovement vertical jump is an appropriate pre-exercise activity. We speculate that the increased spinalreflex excitability in our study was attributed to acute adjustment in neural adaptation due to the Ia presynaptic inhibition [53] and/or motor unit recruitment [54]. The increased spinal-reflex excitability seen in our study gradually decreased toward baseline after a 20 min measurement interval between the post-condition at 0 and $20 \mathrm{~min}$ (Figure 4); this prolonged increase has been reported in previous studies $[55,56]$. Along with no change in vertical jump heights, our observation of spinal-reflex excitability suggests that factors, other than neural activation (e.g., contractile response, temperature change), must play a role in performance enhancement as a PAP stimulus [54]. The Ia spinal-reflex more likely responds to low-intensity contractions [57], which also partly explains why our results did not show statistical differences. An antagonistic effect was expected in the combined condition (stretch and contraction). However, the percent change in spinal-reflex excitability (a 17\% reduction) in this condition was similar to that in the isolated stretch condition, suggesting that the tensional stimulus dampens the contraction stimulus.

\subsection{Limitations and Assumptions}

Training level is one of the contributing factors to the effects of static stretch on athletic performance [58]. Therefore, our subjects were not athletes but recreationally active such that their training background (e.g., experience and frequency of static stretch) must be acknowledged. Additionally, our results for the combined condition were based on three trials of vertical jumps. Typically, a larger volume of dynamic movements as pre-exercise activity are performed; hence, care should be taken not to over-generalize our results. Regarding the spinal-reflex excitability, it should be assumed that each subject's response and adaptation to the stimulus of static stretch were similar across sessions. While a pre-exercise activity including static stretch is performed at every practice (or on a regular basis), we do not know the level of response adaptation due to repetitive stimulation by 
static stretch on jumping performance. Lastly, we calculated the H:M ratio (recorded via the electrodes attached to the VM) to examine the quadriceps spinal-reflex excitability as many previous studies did $[22,29,59,60]$. The H-reflex and M-response were elicited by electrical stimulations to the femoral nerve, which innervates the entire quadriceps muscles. Therefore, we assume that the VM activation was not different to other quadriceps muscles.

\subsection{Practical Implications}

We observed that a $90 \mathrm{~s}$ hold lower quarter static stretch, either alone or in conjunction with vertical jumps, did not alter maximal jumping ability of recreationally active subjects. The observed level of jumping performance after either condition above (static stretch or static stretch followed by vertical jumps) was similar to that after the condition using sport-specific movement (vertical jumps). This also suggests that the isolated or combined effects of our protocols of the static stretch and explosive contraction could be incorporated into a warm-up activity.

\section{Conclusions}

Neither static stretch (in a modified Thomas test using a $30 \mathrm{~s}$ hold $\times 3$ on each leg) nor explosive contraction (using two-legged maximal countermovement vertical jumps $\times 3$ ) changed the quadriceps spinal-reflex excitability, and the latency time of the H-reflex and M-response. Since our stretch protocol did not affect jumping performance and our contraction protocol induced the PAP effect (increased the quadriceps spinal-reflex excitability by $42 \%$ with an ES of 0.63 ), either protocol could be used as a pre-exercise activity.

Author Contributions: Conceptualization, K.E.M. and J.P.; methodology, K.E.M., Y.L., J.P.; software, K.E.M. and Y.L.; formal analysis, K.E.M.; investigation, J.P.; resources, J.P; data curation, K.E.M. and Y.L.; writing — original draft preparation, K.E.M. and J.P.; writing—review and editing, K.E.M. and J.P.; visualization, K.E.M. and J.P.; supervision, J.P.; project administration, J.P. All authors have read and agreed to the published version of the manuscript.

Funding: This work was supported by the IOC Research Centre KOREA, Wonju, Korea.

Institutional Review Board Statement: The study was conducted according to the guidelines of the Declaration of Helsinki and approved by the Institutional Review Board of Kyung Hee University (KHSIRB 2016-010).

Informed Consent Statement: Informed consent was obtained from all subjects involved in the study.

Data Availability Statement: The data are available on request from the corresponding author.

Conflicts of Interest: The authors declare no conflict of interest.

\section{References}

1. Safran, M.R.; Garrett, W.E., Jr.; Seaber, A.V.; Glisson, R.R.; Ribbeck, B.M. The role of warmup in muscular injury pervention. Am. J. Sports Med. 1988, 16, 123-129. [CrossRef]

2. Racinais, S.; Cocking, S.; Périard, J.D. Sports and environmental temperature: From warming-up to heating-up. Temperature 2017, 40, 227-257. [CrossRef]

3. Bobbert, M.F.; Gerritsen, K.G.; Litjens, M.C.; Van Soest, A.J. Why is countermovement jump height greater than squat jump height? Med. Sci. Sports Exerc. 1996, 28, 1402-1412. [CrossRef] [PubMed]

4. Fletcher, I.M.; Monte-Colombo, M.M. An investigation into the possible physiological mechanisms associated with changes in performance related to acute responses to different preactivity stretch modalities. Appl. Physiol. Nut. Metabol. 2010, 35, 27-34. [CrossRef]

5. Behm, D.G.; Chaouachi, A. A review of the acute effects of static and dynamic stretching on performance. Eur. J. Appl. Physiol. 2011, 111, 2633-2651. [CrossRef] [PubMed]

6. Horita, T.; Komi, P.; Nicol, C.; Kyröläinen, H. Stretch shortening cycle fatigue: Interactions among joint stiness, reflex, and muscle mechanical performance in the drop jump. Eur. J. Appl. Physiol. Occup. Physiol. 1996, 73, 393-403. [CrossRef] [PubMed]

7. Hoffman, P. Beitrag zur kenntnis der menschlichen reflexe mit besonderer berucksichtigung der elektrischen erscheinungen. Arch. Anat. Physiol. 1910, 1, 223-246. 
8. Zehr, P.E. Considerations for use of the Hoffmann reflex in exercise studies. Eur. J. Appl. Physiol. 2002, 86, 455-468. [CrossRef]

9. Knikow, M. The H-reflex as a probe: Pathways and pitfalls. J. Neurosci. Methods 2008, 171, 1-12. [CrossRef]

10. Avela, J.; Komi, P.V. Reduced stretch reflex sensitivity and muscle stiffness after long-lasting stretch-shortening cycle exercise in humans. Eur. J. Appl. Physiol. 1998, 78, 403-410. [CrossRef]

11. Komi, P.V.; Gollhofer, A. Stretch reflexes can have an important role in force enhancement during ssc exercise. J. Appl. Biomech. 1997, 13, 451-460. [CrossRef]

12. Grindstaff, T.L.; Pietrosimone, B.G.; Sauer, L.D.; Kerringan, D.C.; Patrie, J.T.; Hertel, J.; Ingersoll, C.D. Manual therapy directed at the knee or lumbopelvic region does not influence quadriceps spinal-reflex excitability. Man. Ther. 2014, 19, 299-305. [CrossRef] [PubMed]

13. Hopkins, J.T.; Ingersoll, C.D.; Krause, B.A.; Edwards, J.E.; Cordova, M.L. Effect of knee joint effusion on quadriceps and soleus motoneuron pool excitability. Med. Sci. Sports Exerc. 2001, 33, 123-126. [CrossRef]

14. Ritzmann, R.; Kramer, A.; Gollhofer, A.; Taube, W. The effect of whole body vibration on the H-reflex, the stretch reflex, and the short-latency response during hopping. Scand. J. Med. Sci. Sports 2013, 23, 331-339. [CrossRef]

15. Nielsen, J.; Petersen, N.; Ballegaard, M.; Biering-Sørensen, F.; Kiehn, O. H-reflexes are less depressed following muscle stretch in spastic spinal cord injured patients than in healthy subjects. Exp. Brain Res. 1993, 97, 173-176. [CrossRef]

16. Avela, J.; Kyröläinen, H.; Komi, P.V. Altered reflex sensitivity after repeated and prolonged passive muscle stretching. J. Appl. Physiol. 1999, 86, 1283-1291. [CrossRef]

17. Hwang, I.S.; Huang, C.Y.; Wu, P.S.; Chen, W.C.; Wang, C.H. Assessment of H reflex sensitivity with $\mathrm{M}$ wave alteration consequent to fatiguing contractions. Int. J. Neurosci. 2008, 118, 1317-1330. [CrossRef]

18. Stuzig, N.; Siebert, T. Assessment of the H-reflex at two contraction levels before and after fatigue. Scand. J. Med. Sci. Sports 2017, 27, 399-407. [CrossRef] [PubMed]

19. Mizner, R.L.; Snyder-Mackler, L. Altered loading during walking and sit-to-stand is affected by quadriceps weakness after total knee arthroplasty. J. Orthop. Res. 2005, 23, 1083-1090. [CrossRef]

20. Keays, S.L.; Bullock-Saxton, J.; Newcombe, P.A.; Keays, A.C. The relationship between knee strength and functional stability before and after anterior cruciate ligament reconstruction. J. Orthop. Res. 2003, 21, 231-237. [CrossRef]

21. Yapicioglu, B.; Colakoglu, M.; Colakoglu, Z.; Gulluoglu, H.; Bademkiran, F.; Ozkaya, O. Effects of a dynamic warm-up, static stretching or static stretching with tendon vibration on vertical jump performance and EMG responses. J. Hum. Kinet. 2013, 39, 49-57. [CrossRef] [PubMed]

22. Park, J.; Hopkins, J.T. Immediate effects of acupuncture and cryotherapy on quadriceps motoneuron pool excitability: Randomised trial using anterior knee infusion model. Acupuncrt. Med. 2012, 30, 195-202. [CrossRef] [PubMed]

23. Kolosova, E.V.; Slivko, É.I. Fatigue-induced modulation of the H reflex of soleus muscle in humans. Neurophysiology 2006, 38, 360-364. [CrossRef]

24. Harvey, D. Assessment of the flexibility of elite athletes using the modified Thomas test. Br. J. Sports Med. 1998, 32, 68-70. [CrossRef]

25. Cronin, J.; Nash, M.; Whatman, C. The acute effects of hamstring stretching and vibration on dynamic knee joint range of motion and jump performance. Phys. Ther. Sport 2008, 9, 89-96. [CrossRef]

26. Behm, D.G.; Bambury, A.; Cahill, F.; Power, K. Effect of acute static stretching on force, balance, reaction time, and movement time. Med. Sci. Sports Exerc. 2004, 36, 1397-1402. [CrossRef] [PubMed]

27. Palmieri, R.M.; Ingersoll, C.D.; Hoffman, M.A. The Hoffmann reflex: Methodologic considerations and applications for use in sports medicine and athletic training research. J. Athl. Train. 2004, 39, 268-277. [PubMed]

28. Gajewski, J.; Mazur-Różycka, J. The H-reflex as an important indicator in kinesiology. Hum. Mov. 2016, 17, 64-71. [CrossRef]

29. Park, J.; Hopkins, J.T. Induced anterior knee pain immediately reduces involuntary and voluntary quadriceps activation. Clin. J. Sport Med. 2013, 23, 19-24. [CrossRef]

30. Cohen, J. Quantitative methods in psychology: A power primer. Psychol. Bull. 1992, 112, 155-159. [CrossRef]

31. Thomas, J.; Nelson, J. Research Methods in Physical Activity, 5th ed.; Human Kinetics: Champaign, IL, USA, 2005 ; pp. 196-200.

32. Burke, D. Clinical uses of $\mathrm{H}$ reflexes of upper and lower limb muscles. Clin. Neurophysiol. Pract. 2016, 1, 9-17. [CrossRef] [PubMed]

33. McNeal, J.R.; Sands, W.A. Acute static stretching reduces lower extremity power in trained children. Pediatr. Exerc. Sci. 2003, 15, 139-145. [CrossRef]

34. González-Ravé, J.M.; Machado, L.; Navarro-Valdivielso, F.; Vilas-Boas, J.P. Acute effects of heavy-load exercises, stretching exercises, and heavy-load plus stretching exercises on squat jump and countermovement jump performance. J. Strength Cond. Res. 2009, 23, 472-479. [CrossRef]

35. Dalrymple, K.J.; Davis, S.E.; Dwyer, G.B.; Moir, G.L. Effect of static and dynamic stretching on vertical jump performance in collegiate women volleyball players. J. Strength Cond. Res. 2010, 24, 149-155. [CrossRef]

36. Kay, A.D.; Blazevich, A.J. Reductions in active plantar flexion moment are significantly correlated with static stretch duration. Eur. J. Sports Sci. 2008, 8, 41-46. [CrossRef]

37. McHugh, M.P.; Cosgrave, C.H. To stretch or not to stretch: The role of stretching in injury prevention and performance. Scand. J. Med. Sci. Sports 2010, 20, 169-181. [CrossRef] [PubMed] 
38. Jang, H.S.; Kim, D.; Park, J. Immediate effects of different types of stretching exercises on badminton jump smash. J. Sports Med. Phys. Fit. 2018, 58, 1014-1020.

39. Brandenburg, J.; Pitney, W.A.; Luebbers, P.E.; Veera, A.; Czajka, A. Time course of changes in vertical-jumping ability after static stretching. Int. J. Sports Physiol. Perform. 2007, 2, 170-181. [CrossRef] [PubMed]

40. Samuel, M.N.; Holcomb, W.R.; Guadagnoli, M.A.; Rubley, M.D.; Wallmann, H. Acute effects of static and ballistic stretching on measures of strength and power. J. Strength Cond. Res. 2008, 22, 1422-1428. [CrossRef]

41. Pinto, M.D.; Wilhelm, E.N.; Tricoli, V.; Pinto, R.S.; Blazevich, A.J. Differential Effects of 30-vs. 60-Second Static Muscle Stretching on Vertical Jump Performance. J. Strength Cond. Res. 2014, 28, 3440-3446. [CrossRef]

42. Bogdanis, G.C.; Donti, O.; Tsolakis, C.; Smilios, I.; Bishop, D.J. Intermittent but not continuous static stretching improves subsequent vertical jump performance in flexibility-trained athletes. J. Strength Cond. Res. 2019, 33, 203-210. [CrossRef] [PubMed]

43. Kay, A.D.; Blazevich, A.J. Effect of acute static stretch on maximal muscle performance: A systematic review. Med. Sci. Sports Exerc. 2012, 44, 154-164. [CrossRef]

44. Simic, L.; Sarabon, N.; Markovic, G. Does pre-exercise static stretching inhibit maximal muscular performance? A meta-analytical review. Scand. J. Med. Sci. Sports 2013, 23, 131-148. [CrossRef]

45. Rehn, B.; Lidstrom, J.; Skoglund, J.; Lindstrom, B. Effects on leg muscular performance from whole-body vibration exercise: A systematic review. Scand. J. Med. Sci. Sports 2007, 17, 2-11. [CrossRef]

46. Latash, M.L. Neurophysiological Basis of Movement, 2nd ed.; Human Kinetics: Champaign, IL, USA, 2007.

47. Kröger, S.; Watkins, B. Muscle spindle function in healthy and diseased muscle. Skelet. Muscle 2021, 11, 3. [CrossRef]

48. Sharman, M.; Cresswell, A.G.; Riek, S. Proprioceptive neuromuscular facilitation stretching: Mechanisms and clincial implications. Sports Med. 2006, 36, 929-939. [CrossRef] [PubMed]

49. Burke, R.; Rudomin, P.; Zajac, F. The effect of activation history on tension production by individual muscle units. Brain Res. 1976, 109, 515-529. [CrossRef]

50. Robbins, D.W. Postactivation potentiation and its practical applicability: A brief review. J. Strength Cond. Res. 2005, 19, 453-458. [CrossRef] [PubMed]

51. Toumi, H.; Poumarat, G.; Benjamin, M.; Best, T.; F'Guyer, S.; Fairclough, J. New insights into the function of the vastus medialis with clinical implications. Med. Sci. Sports Exerc. 2007, 39, 1153-1159. [CrossRef]

52. Cowan, S.M.; Bennell, K.L.; Hodges, P.W.; Crossley, K.M.; McConnell, J. Delayed onset of electromyographic activity of vastus medialis obliquus relative to vastus lateralis in subjects with patellofemoral pain syndrome. Arch. Phys. Med. Rehabil. 2001, 82, 183-189. [CrossRef]

53. Layec, G.; Bringard, A.; Fur, Y.L.; Vilmen, C.; Micallef, J.-P.; Perrey, S.; Cozzone, P.; Bendahan, D. Effects of a prior high-intensity knee-extension exercise on muscle recruitment and energy cost: A combined local and global investigation in humans. Exp. Physiol. 2009, 94, 704-719. [CrossRef]

54. Blazevich, A.J.; Babault, N. Post-activation potentiation versus post-activation performance enhancement in humans: Historical perspective, underlying mecahnisms, and current issues. Front. Physiol. 2019, 10, 1-19. [CrossRef]

55. Trimble, M.H.; Harp, S.S. Prostexercise potentiation of the H-reflex in humans. Med. Sci. Sports Exerc. 1998, 30, 933-941.

56. Folland, J.P.; Wakamatsu, T.; Fimland, M.S. The influence of maximal isometric activity on twitch and H-reflex potentiation, and quadriceps femoris performance. Eur. J. Appl. Physiol. 2008, 104, 739-748. [CrossRef]

57. Vila-Chã, C.; Falla, D.; Correia, M.V.; Farina, D. Change in H reflex and V wave following short-term endurance and strength training. J. Appl. Physiol. 2012, 112, 54-63. [CrossRef]

58. Lima, C.D.; Brown, L.E.; Wong, M.; Levya, W.D.; Pinto, R.S.; Cadore, E.L.; Ruas, C.V. Acute effects of static vs. ballistic stretching on strength and muscular fatigue between ballet dancers and resistance trained women. J. Strength Cond. Res. 2016, 30, 3220-3227. [CrossRef] [PubMed]

59. Alrowayeh, H.N.; Sabbahi, M. Vastus medialis H-reflex reliability during standing. J. Clin. Neurophysiol. 2006, 23, 79-84. [CrossRef] [PubMed]

60. Marshall, P.W.; Rasmussen, S.B.; Krogh, M.; Halley, S.; Siegler, J.C. Changes in the quadriceps spinal-reflex pathway after repeated sprint cycling are not influenced by ischemic preconditioning. Eur. J. Appl. Physiol. 2020, 120, 1189-1202. [CrossRef] [PubMed] 